\title{
ESTUDO SOBRE AS EXPERIÊNCIAS VIVENCIADAS POR UM GRUPO DE MOÇAMBICANOS EM CAPACITAÇÃO NO BRASIL.
}

\author{
Anna Ariane Araújo de LAVOR ${ }^{1}$ \\ Margarita Rosa Gaviria MEJÍA²
}

\begin{abstract}
Resumo
O presente artigo visa analisar elementos institucionais, transnacionais e culturais que interferiram nas relações de quatro moçambicanos, que participaram de um programa de qualificação na Rede Federal de Educação no Brasil. Foram realizadas entrevistas semi estruturadas para atingir o objetivo da investigação. Percebeu-se que o preconceito étnico e racial dos brasileiros e a percepção moçambicana estigmatizada sobre a homossexualidade representaram barreiras culturais entre os países. Contudo, estas situações não impediram a troca de experiências técnicas e culturais ocorridas no Brasil.
\end{abstract}

Palavras-chave: Mobilidade. Transnacionalismo. Educação.

\section{STUDY ON THE EXPERIENCES OF A GROUP OF MOZAMBICANS IN TRAINING IN BRAZIL.}

\begin{abstract}
This article aims to analyze the transnational and cultural institutional elements that interfered in the relations of four Mozambicans, who participated in a qualification program in the Federal Network of Education in Brazil. Semistructured interviews were carried out to reach the research objective. It was noticed that the ethnic and racial prejudice of the Brazilians and the Mozambican perception stigmatized on the homosexuality represented cultural barriers between the countries. However, these situations did not prevent the exchange of technical and cultural experiences in Brazil.
\end{abstract}

Keywords: Mobility. Transnationalism. Education

\footnotetext{
1 Doutoranda em Ambiente e Desenvolvimento pela Universidade do Vale do Taquari (UNIVATES). E-mail: annaariane@hotmail.com

${ }^{2}$ Profa. Dra. Do Programa de Pós-Graduação em Ambiente e Desenvolvimento (PPGAD) e no Centro de Ciências Sociais (CCHS) da Universidade do Vale do Taquari (UNIVATES). E-mail: margaritarosagaviria@gmail.com
} 


\section{ESTUDIO DE EXPERIENCIAS EXPERIMENTADAS POR UN GRUPO DE MOZAMBICANOS EN FORMACIÓN EN BRASIL.}

\section{Resumen}

Este artículo tiene como objetivo analizar elementos institucionales, transnacionales y culturales que interfirieron en las relaciones de cuatro mozambiqueños, que participaron en un programa de calificación en la Red Federal de Educación en Brasil. Se realizaron entrevistas semiestructuradas para lograr el objetivo de la investigación. Se observó que el prejuicio étnico y racial de los brasileños y la estigmatizada percepción mozambiqueña de la homosexualidad representaban barreras culturales entre los países. Sin embargo, estas situaciones no impidieron el intercambio de experiencias técnicas y culturales que ocurrieron en Brasil.

Palabras clave: Movilidad. Transnacionalismo. Educación

\section{INTRODUÇÃO}

O Governo de Moçambique implementou em 2006 a Reforma da Educação Profissional (REP), também designada Programa Integrado da Reforma da Educação Profissional (PIREP), que contempla ações previstas até 2020 (Pinto, 2015). Dentre as ações propostas para melhorar a qualidade da educação profissional se destacam a qualificação do quadro de formadores, o aprimoramento da infraestrutura e a provisão de equipamento e materiais de aprendizagem para as instituições, de modo a adequá-las às exigências estabelecidas no âmbito da PIREP (Moçambique,2006).

Tal como Castro e Neto (2012) argumentam, as reformas na educação são indispensáveis para uma adaptação às novas necessidades da economia mundial globalizada, pois funcionam como uma estratégia para melhorar a competitividade de um país. Assim, o propósito do governo moçambicano é “investir na reabilitação, apetrechamento e modernização das instituições do ensino-técnico profissional, com vista ao estabelecimento e consolidação de um sistema de educação de qualidade e que responda às exigências do mercado de trabalho" (Jornal Notícias, 2018).

Para alcançar essas metas, o governo de Moçambique realizou várias parcerias, uma delas com o governo brasileiro, por meio do Conselho Nacional das Instituições da Rede Federal de Educação Profissional, Científica e 
Tecnológica (CONIF). Assim, o governo de Moçambique firmou um convênio com o CONIF, para a realização de programas de intercâmbio visando a qualificação de estudantes, professores, palestrantes, gestores e especialistas dos dois países (Moçambique, 2017). As áreas de intervenção da Reforma da Educação Profissional em curso incluem o setor da agricultura, através da implementação de novos currículos baseados em padrões de competência nos institutos médios agrários (Moçambique, 2017). Para melhorar o desenvolvimento de Moçambique se priorizou a atenção na área agrária (Moçambique, 2008).

Segundo o CONIF (2017), a parceria entre os dois países foi firmada após uma visita, em 2016, do Cônsul de Moçambique a um dos Institutos Federais de Educação do Brasil. Na visita, a autoridade moçambicana se entusiasmou com a infraestrutura e ações de formação praticadas. Como resultado dessa visita, o CONIF (2017) viu a possibilidade de trabalhar com um país com o qual não apenas tem muitas afinidades culturais, mas também coincidem em reconhecer o potencial da educação tecnológica. Esta conjuntura favorece a troca de experiências válida entre os dois países nesse processo de internacionalização. Ficou então decidido que o CONIF iria receber 30 formadores moçambicanos com o grau de licenciatura em agronomia para participar de cursos em módulos diversos nas Instituições de ensino Técnico Profissional da área Agrária (Moçambique, 2017). A formação teve a duração de 3 meses nos Institutos Federais da rede CONIF no Brasil e os moçambicanos se dividiram em pequenos grupos para visitar diversos campi da rede federal de ensino. Nessas visitas cada grupo fez curso de capacitação em 3 Institutos Federais (Jornal A Praça, 2018).

De acordo com o Protocolo de Intenções firmado entre o governo de Moçambique e o CONIF do Brasil, embora o foco principal do intercâmbio seja a qualificação profissional, cada país deverá se empenhar em criar "condições que permitam aos cidadãos da outra parte conhecer a sua cultura, história, literatura, geografia, costumes e tradições" (Moçambique, 2017, p. 10). Nesse sentido, é explícita a intenção de que ocorra uma troca de experiências e conhecimentos que transcendam a aprendizagem que acontece nas salas de aula, valorizando as vivências decorrentes do encontro entre culturas diferentes. 
O principal objetivo desses cursos é a consolidação dos atuais conhecimentos e habilidades dos professores da área agrícola. Os cursos deverão considerar o domínio do uso prático e a maximização das potencialidades dos equipamentos disponíveis nas áreas de Mecanização Agrária, Solos, Irrigação, Extensão Agrária e Sistemas de Produção (Moçambique, 2018).

O presente artigo visa, através do conhecimento da experiência de quatro professores moçambicanos que participaram do programa nos Institutos Federais de São Luís - MA, Iguatu - CE e Petrolina - PE, analisar elementos institucionais transnacionais (convênio entre os dois países) e culturais que interferem nas relações dos moçambicanos com o Brasil. As reflexões sobre a experiência de moçambicanos durante a estada em Institutos Federais do Brasil, se deu em torno de três questões:

- Quais são os projetos transnacionais que dão suporte à mobilidade educacional?

- Como se refletem os projetos transnacionais nas experiências profissionais dos moçambicanos no Brasil?

- Em que medida os elementos culturais interferem na realização dos projetos transnacionais que envolvem Brasil e Moçambique?

\section{METODOLOGIA}

A coleta de dados da pesquisa foi realizada por meio de entrevistas semi estruturadas dirigidas aos quatro professores moçambicanos que estiveram assistindo a curso de capacitação no Brasil, acompanhando a vida acadêmica dos campi, participando de aulas teóricas e práticas com os alunos dos campi e em aulas especificamente preparadas para seu treinamento (IFCE, 2018) nos Institutos Federais de São Luís - MA, Iguatu - CE e Petrolina - PE.

As entrevistas semiestruturadas foram o recurso utilizado para conhecer as experiências vivenciadas pelos professores moçambicanos. Neste tipo de entrevista são "acrescentadas perguntas ao roteiro prévio na medida em que ocorrem novos aspectos na entrevista” (CHEMIN, 2015, p. 67). Por ser uma modalidade de entrevista não dirigida, possibilita ao entrevistado liberdade para 
expressar sentimentos e opiniões, de forma que o entrevistador apenas incentiva o entrevistado a falar sobre determinado assunto, sem direcionar ou forçar as respostas. No decorrer das entrevistas indagou-se sobre motivos pessoais e profissionais que estimularam a participação dos professores moçambicanos nos projetos transnacionais e como estas estão sendo vivenciadas no Brasil. Além disso, foram colocadas questões dirigidas para analisar em que medida os elementos culturais interferiram na realização dos projetos transnacionais que envolvem Brasil e Moçambique. Os resultados das entrevistas foram tabulados por tema e analisados, buscando extrair as principais ideias apresentadas pelos entrevistados, a fim de alcançar os objetivos propostos neste trabalho.

\section{ACORDOS INTERNACIONAIS DE COLABORAÇÃO TÉCNICA}

A mobilidade estudantil a nível internacional é facilitada pelos Acordos de Colaboração Técnica entre países com interesses em comum. Assim, um projeto de estudos individual representa também um projeto de Estado. A mobilidade estudantil implica uma educação sem fronteiras, onde não circulam apenas pessoas, mas também ideias, expressões, saberes e culturas dentro de projetos transnacionais (ZAMBERLAM et al., 2009). Morales (2009) defende que a ideia da imigração como uma rede social transnacional ocorre quando a mesma não é determinada apenas por decisões racionais individuais ou por uma valoração completamente voltada para o mercado de trabalho, como é o caso da migração estudantil, onde estes imigrantes são motivados por projetos familiares, culturais e econômicos, que vão além das fronteiras.

A cooperação técnica internacional é uma prática que auxilia o Brasil a promover um desenvolvimento integrado e mudanças estruturais nas esferas social e econômica. As ações são planejadas conforme as demandas de países cooperados, compartilhando conhecimentos, experiências e boas-práticas na educação, saúde, economia, dentre outras áreas (AGÊNCIA BRASILEIRA DE COMUNICAÇÕES, 2019a).

Segundo a Agência Brasileira de Comunicações (2019a), na década de 1970, o acúmulo de práticas positivas dos países em desenvolvimento, 
suscetíveis de serem transmitidas a países que se encontram no mesmo grau de desenvolvimento, levou as Nações Unidas a criar o conceito de "Cooperação Técnica entre Países em Desenvolvimento" (CTPD) ou "Cooperação Horizontal", também conhecida como Cooperação Sul-Sul, em contraponto à "Cooperação Norte - Sul”. Desta forma, o Programa Sul-Sul busca a integração entre as nações do Atlântico Sul e Ásia, almejando o progresso por meio de uma cooperação solidária (RIBEIRO, 2016).

Em 1974 foi criada a Unidade Especial para CTPD no âmbito do PNUD, iniciando-se os estudos para o fomento a essa modalidade de cooperação. Em 1978, as diretrizes elaboradas foram propostas na Conferência das Nações Unidas sobre Cooperação Técnica entre Países em Desenvolvimento e suas recomendações aprovadas na forma do Plano de Ação de Buenos Aires. (AGÊNCIA BRASILEIRA DE COMUNICAÇÕES, 2019a, online)

Essa conferência trouxe um novo conceito de cooperação, defendendo o compartilhamento de informações entre os países em desenvolvimento nas áreas de educação, saúde e agricultura (SOUSA, 2015). Assim, a Cooperação técnica entre países, em especial a Cooperação Sul-Sul, se consolida como uma ferramenta eficaz na troca de conhecimentos específicos entre os países participantes.
A cooperação técnica Sul-Sul bilateral do Brasil está concentrada nas áreas de agricultura (incluindo produção agrícola e segurança alimentar), formação profissional, educação, justiça, esporte, trabalho, desenvolvimento urbano, biocombustível, transporte aéreo e saúde, meio ambiente, tecnologia da informação, prevenção de acidente de turismo. Outras áreas como cultura, comércio exterior e direitos humanos, estão contempladas em projetos e atividades de concepção mais recente. (AGÊNCIA BRASILEIRA DE COMUNICAÇÕES, 2019b, online)

A proximidade histórica cultural do Brasil com os demais países lusófonos faz com que o governo brasileiro estreite os laços com os membros da Comunidade dos Países de Língua Portuguesa (CPLP), criada em 1996. Como parte das ações internacionais destinadas a minorar o impacto da exclusão econômica e social em países que apresentam grandes obstáculos para o desenvolvimento, o governo brasileiro promove diversos projetos de cooperação com os Países Africanos de Língua Oficial Portuguesa (PALOP) (AGÊNCIA BRASILEIRA DE COMUNICAÇÕES, 2018b). Um dos projetos gerados por essa 
cooperação é o convênio entre o governo de Moçambique com o CONIF, através do qual se realiza um intercâmbio de conhecimentos acadêmicos entre os professores de cursos técnicos da área agrária de Moçambique e a rede Federal de Ensino Técnico e Tecnológico no Brasil.

A cooperação técnica entre o Brasil e Moçambique é amparada pelo "Acordo Geral de Cooperação entre a República Federativa do Brasil e a República de Moçambique", assinado em 15 de setembro de 1981 e promulgado somente em o9 de junho de 1984 (AGÊNCIA BRASILEIRA DE COMUNICAÇÕES, 2012). O acordo é composto por 21 projetos, dentre os quais se destacam os da área de segurança alimentar, alimentação escolar, combate ao vírus do HIV e fortalecimento do Poder judiciário (AGÊNCIA BRASILEIRA DE COMUNICAÇÕES, 2012). Inclui também projetos na área de Educação, como a criação da Universidade Aberta do Brasil em Moçambique e a participação de Moçambique no Programa de Estudantes-Convênio de Graduação (PEC-G).

\section{IMIGRAÇÃO AFRICANA NO BRASIL}

A mobilidade populacional na África é constante. Segundo o Jornal El País (2018), 36 milhões de africanos migraram em 2017, equivalente a 14\% dos 258 milhões de deslocamentos registrados no ano passado em todo mundo. Em 2015, o continente africano apresentou a maior proporção de jovens migrantes internacionais (de 15 a 24 anos) com 34\% do total. Estes jovens saem em busca de melhores oportunidades de vida, trabalho e/ou educação. Em relação a Moçambique, este país foi historicamente mais emissor de migrantes para os países vizinhos, principalmente para a África do Sul. Entretanto, com a estabilidade política após o fim da guerra civil, o acelerado crescimento econômico e a descoberta de recursos minerais, percebe-se uma acentuada entrada de imigrantes, incluindo refugiados, provenientes de todos os continentes (MUANAMOHA E RAIMUNDO, 2018; PATRÍCIO E PEIXOTO, 2018).

O foco deste artigo é na migração estimulada pela educação. Esse fluxo migratório dos africanos para o Brasil, impulsionado pelos Acordos Educacionais Internacionais, acontece a partir dos anos 1960 (TCHAM, 2016). 
O número de imigrantes aumentou nos últimos anos devido a uma política de cooperação e de aproximação com a África (SILVA, 2017). Dados estatísticos indicam que o contingente populacional de africanos no Brasil se multiplicou 30 vezes entre 2000 e 2012 (TERRA, 2014).

No âmbito do Brasil, o Ceará é atualmente um dos estados com maior número de estudantes oriundos da África. São cerca de 3000 imigrantes africanos, 272 destes encontram-se em Redenção - CE e o restante concentrase, principalmente, em Fortaleza-CE (DIÁRIO DO NORDESTE, 2015). De acordo com Langa (2016), os estudantes africanos representam 82,3\% do total de estrangeiros que entraram no Ceará em 2015.

Langa (2015) relata que a maioria destes estudantes africanos estudam em faculdades particulares, custeados pelos familiares e/ou trabalhos informais em lojas, mercadinhos, salões de belezas, oficinas ou serviços domésticos em residências. Estes imigrantes vêm com finalidade estudantil, contudo, devido ao alto custo de vida, iniciam trabalhos informais para se manterem no Brasil. Na época da pesquisa feita por Langa (2015), o Brasil não permitia o trabalho formal de quem possuía visto de estudante no país, por isso, conforme relatado pelo autor, os estudantes eram obrigados a se submeterem a trabalhos informais. Apenas em dezembro de 2016, o Brasil passou a conceder vistos de estudo e trabalho para os estudantes estrangeiros de graduação ou pósgraduação no país, por meio da Resolução Normativa ${ }^{0}{ }^{124}$, de 13 de dezembro de 2016 (BRASIL, 2016).

Uma minoria de imigrantes africanos no Brasil ingressa nas universidades públicas federais (por exemplo: UFC, UNILAB) ou estaduais (UECE e outras), custeados pelas bolsas do Programa de Estudantes-Convênio de Graduação e outros convênios acordados com seus países de origem. O Programa de Estudantes-Convênio de Graduação (PEC-G) foi criado em 1965 para amparar estudantes de outros países, num contexto em que há uma expansão de estrangeiros no Brasil (DCE, 2018).

De acordo com Subuhana (2008), Langa (2014) e Fonseca (2015), o idioma é uma das principais justificativas para os estudantes africanos escolherem o Brasil. Langa (2014) acrescenta ainda o fato do Brasil possuir maior nível de desenvolvimento econômico, tecnológico e de produção 
acadêmica. Enquanto Subuhana (2008), ressalta os laços de amizade entre o Brasil com os Palop, bem como suas especificidades históricas, sociais, econômicas, educacionais e culturais. Os Países Africanos de Língua Oficial Portuguesa (Palop) são países que possuem área de interesse e influência de Portugal e Brasil, pela ligação histórico-social e cultural, "geradas pela presença portuguesa em seus territórios, tendo o comércio como eixo, aliado à escravização de africanos, cujo principal destino era o Brasil" (RIZZI, 2016, p. 145).

\section{ANÁLISE DOS RESULTADOS}

Conforme já exposto, as reflexões são elaboradas tomando como eixo a experiência de 04 professores moçambicanos que estavam assistindo a curso de capacitação no Brasil, dentro do convênio entre o governo de Moçambique e o Conselho Nacional das Instituições da Rede Federal de Educação Profissional, Científica e Tecnológica (CONIF) do Brasil. As entrevistas e a observação foram realizadas quando o grupo se encontrava no IFCE da cidade de Iguatu - CE. Os professores entrevistados possuem Licenciatura em Agronomia e trabalham em Instituições de ensino Técnico Profissional da área agrária em diferentes cidades de Moçambique.

De acordo com Ballerini e Silva (2015), a mobilidade estudantil costuma ser acompanhada pela busca de oportunidades pessoais, educacionais e profissionais. E este pressuposto foi confirmado no decorrer das entrevistas. Ao serem questionados pelos motivos que os fizeram optar pela capacitação no Brasil, os entrevistados relataram principalmente a necessidade de novos conhecimentos. Nos termos de um deles, estava interessado em "adquirir novos conhecimentos, desenvolver as capacidades e habilidades pessoais e profissionais, enriquecendo assim o corpo docente da instituição na qual sou funcionário" (ENTREVISTADO 02).

Os entrevistados relataram que procuram aproveitar todas as oportunidades encontradas no Brasil para desenvolver os conhecimentos, já que em Moçambique não é fácil conseguir qualificação profissional. Nesse país qualquer capacitação precisa ser custeada pelo estudante ou por seus familiares. 
Um dos entrevistados inclusive afirmou que recentemente surgiu uma oportunidade para fazer um mestrado na área agrícola, em uma Universidade moçambicana, contudo, os financiadores depois desistiram das bolsas que iriam ser concedidas, impossibilitando a realização do curso.

Contudo, o objetivo da formação adquirida no Brasil, da ótica de um dos moçambicanos entrevistados,

é um fator importante para o desenvolvimento do ensino e aprendizagem no país, e dada a demanda em que o país possui, acredito que irei contribuir na busca de soluções alternativas para o presente e perspectivar melhor as ações do futuro no aumento da produtividade no setor de produção. (ENTREVISTADO 1)

No discurso se percebe que mais do que uma viagem para qualificação profissional, o treinamento no Brasil representa um projeto de vida que busca favorecer uma coletividade. Enquanto estão estudando no Brasil pensam em sua contribuição para melhorar o país de origem. Através das falas dos entrevistados, identificam-se duas motivações principais no deslocamento para o Brasil. Uma, adquirir novos conhecimentos, desenvolver capacidades e habilidades pessoais e profissionais. A outra, contribuir no desenvolvimento do ensino e aprendizagem no país.

Quanto às expectativas iniciais em relação ao curso, informaram que aspiravam aprender novas práticas, melhorar o currículo, bem como contribuir na qualidade do ensino praticado no país de origem. Felizmente, estas expectativas foram prontamente atendidas. Os entrevistados consideraram que o Brasil apresenta melhor nível de conhecimento técnico e pedagógico.

Além das expectativas educacionais e profissionais, os entrevistados esperavam conhecer a fundo a cultura brasileira no cotidiano. Quanto às expectativas em relação ao Brasil, percebe-se que estas são perpassadas por uma imagem veiculada pelas novelas brasileiras, as quais são amplamente consumidas em solo moçambicano. Contudo, provavelmente, por terem passado um curto espaço de tempo (3 meses) no Brasil, de acordo com as falas parece que saíram do Brasil com uma percepção semelhante à que tinham ao chegar. As falas de dois entrevistados ilustram a concepção que estes têm do Brasil.

Em uma delas, o Brasil é qualificado como um país muito desenvolvido: "Para quem está em Moçambique, olhar para o Brasil é como olhar para um país 
de primeiro mundo. Um país desenvolvido, que tem um pouco de tudo". (ENTREVISTADO, 1). Na outra expressam a influência da cultura brasileira em Moçambique, veiculada pela tecnologia da comunicação. "Em Moçambique se consome alguns produtos culturais do Brasil, como músicas e novelas, que nos davam uma ideia de como é o país" (ENTREVISTADO, 2).

Argumentam também que a imagem que possuem do Brasil é de "um país do futuro" e um destino "mais atraente" em termos de renda e custo de vida, quando comparado a outros países. Tais depoimentos confirmam a visão de Subuhana (2007, p. 326) ao afirmar que:

Uns chegaram a imaginar que o Brasil fosse um "paraíso social”, sinônimo de desenvolvimento e progresso, portanto, de uma vida farta e de oportunidades incomensuráveis para todos, chegando a pensar que o estilo de vida e o Brasil mostrado nas telenovelas da Rede Globo de Televisão e da Rede Record (Miramar, em Moçambique) era o Brasil real, ou seja, o Brasil que eles haveriam de encontrar. Existe aqui "uma contradição muito grande entre mídia e o que o país exatamente é" (Faztudo). Mas há aqueles que já conheciam a realidade brasileira por meio de "e/imigrantes ativos", amigos, parentes, ou mesmo por leituras e por outras fontes de informação, como os telejornais dos canais de TV citados.

A exaltação positiva da imagem do Brasil é compreensível, tendo em conta que se deriva do imaginário europeu que apela para um Brasil exótico e repleto de oportunidades. Assemelha-se a um lugar desejado, chamado de "El dorado", que na imaginação popular era coberto de riquezas, o que estimulou os empreendimentos da conquista colonizadora (SILVA, 2006).

Quando indagados sobre como iriam utilizar os conhecimentos adquiridos aqui em Moçambique, relataram que compartilhariam suas vivências em diversos espaços, para além da sala de aula, com a comunidade onde vivem, através de projetos de extensão rural:

Vou tentar disseminar ou partilhar este conhecimento adquirido cá, com os alunos e os demais professores, que também é preciso partilhar algumas informações. Mas é algo para além dos colegas de serviço, é também para levar à comunidade. Eu trabalho com extensão rural e agricultura sustentável, que aqui também é chamada de agroecologia e nosso país é basicamente suportado pela agricultura e esta agricultura é praticada pelo setor familiar. E esse setor familiar é caracterizado por pessoas com menos renda. Então em função daquilo que tivemos nas aulas práticas, aprendemos certas técnicas de baixo custo e isto, na minha maneira de pensar, é 
possível implementar dentro das nossas comunidades e conseguir uma melhor produção, com menor custo, gerando um aumento na renda básica familiar. (ENTREVISTADO 3)

É perceptível a importância do pensamento comunitário para os moçambicanos. Subuhana (2009) afirma que a ideia de coletividade costuma estar muito presente nas tradições culturais moçambicanas. Acerca desse posicionamento se manifesta um dos entrevistados nos seguintes termos: “acredito que esta oportunidade poderá transmitir e acrescentar valor ao conhecimento que já possuo, favorecendo o meu empenho em prol do desenvolvimento da minha Instituição bem como da comunidade a qual estou inserido" (ENTREVISTADO 4). Nessa fala perpassa a ideia de que os projetos de capacitação e formação profissional são desenvolvidos com foco em interesses coletivos. Embora sejam projetos de estudos individuais, visam a beneficiar as comunidades e esta é a pretensão de mobilidades internacionais que envolvem projetos transnacionais, como este entre Brasil e Moçambique. Esta visão confirma o que foi dito por Sayad (1998 apud SEYFERTH, 2014, p. 12), ao explicar que "a migração é um fato coletivo e individual, as experiências singulares de mobilidade podem esclarecer aspectos da dimensão coletiva, instrumentalizando a teoria da migração”.

De acordo com os entrevistados, após o encerramento dos treinamentos, ocorreu um encontro com os outros moçambicanos em Brasília -DF, onde se reuniram para trocarem informações sobre o foco das questões aprendidas em cada instituição visitada. A ideia era mostrar como em cada visita o conteúdo programático das atividades diferiam e também quais semelhanças foram verificadas.

Assim, no Instituto Federal de Educação, Ciências e Tecnologia do Maranhão - campus São Luís, onde iniciou a capacitação, o foco de estudo era na "Extensão Rural". Os objetivos principais desta etapa eram: compreender os fundamentos da sociologia e sua relação com o desenvolvimento e a extensão rural; compreender o campo de trabalho do profissional das ciências agrárias, analisando quem são os atores sociais, como e porque atuam de determinada forma, condicionados por fatores históricos; conhecer e desenvolver metodologias de assistência técnica e extensão rural; desenvolver habilidades 
para atuar no meio rural através da aplicação de técnicas de diagnóstico e planejamento participativo.

A segunda etapa aconteceu no Instituto Federal de Educação, Ciências e Tecnologia do Ceará - campus Iguatu. Nesse Instituto, o tema central da capacitação foi a "Irrigação". Tendo como objetivos principais: manejar a água em agroecossistemas, visando beneficiar a produção agropecuária com mínimo impacto ambiental; identificar o método de irrigação mais adequado para cada realidade; planejar, orientar, avaliar e monitorar o uso de sistemas de irrigação.

E a terceira etapa foi no Instituto Federal de Educação, Ciências e Tecnologia de Pernambuco - campus Petrolina. Neste Instituto, o foco do treinamento foi na Mecanização Agrícola. Os objetivos centrais eram: conhecer os aspectos básicos de constituição e funcionamento das máquinas agrícolas; conhecer e praticar atividades de mecanização agrícola necessárias à implantação e condução das principais culturas.

Uma vez finalizado o Curso de Capacitação nos Institutos Federais no Brasil, ao retornar para suas instituições de origem, cada um dos professores moçambicanos tem o compromisso de apresentar um projeto a ser desenvolvido nas instituições de ensino, que envolva interesses das comunidades e das famílias que habitam nos locais onde as suas instituições se encontram inseridas. Esses projetos devem abordar um ou mais assuntos apreendidos no decorrer do curso realizado no Brasil. E uma vez analisado e aprovado o projeto pela instituição, a proposta pode se transformar em projeto de extensão rural.

Ao longo das conversas, os interlocutores colocavam em pauta as semelhanças e diferenças entre Brasil e Moçambique, percebidas por eles nos campos da cultura, do ensino e das técnicas de trabalho. Quanto ao ensino, assinalaram que a forma de se relacionar e os espaços de convivência entre os professores e alunos nas instituições de ensino no Brasil são menos formais do que os estabelecidos entre esses mesmos atores sociais em Moçambique. Em Moçambique, a relação entre alunos e professores é mais hierárquica, os alunos assumem uma posição subordinada diante dos professores, perpassa certa reverência no trato dos alunos. Por outra parte, nessas comparações, ressaltam que os métodos de ensino e as técnicas de trabalho da agricultura, de acordo com um dos entrevistados são, na maior parte das culturas, parecidas. As 
diferenças, segundo o mesmo interlocutor, estão no manejo dos recursos, na forma "como estas culturas são produzidas, ao longo do ano. Em Moçambique basicamente os agricultores confiam nas chuvas e usam as correntes dos rios. Quase não temos sistemas de irrigação. Na agricultura familiar é algo inexistente". (ENTREVISTADO 2).

Outro entrevistado ratificou o argumento acerca dos elementos que diferenciam os recursos tecnológicos entre ambos os países. Afirma que "a outra questão é como esses recursos estão sendo manipulados, por exemplo, em relação a água. Aqui os pequenos agricultores têm seus açudes. Lá, apenas os grandes têm as represas”. Desta forma, corrobora a ideia de que a agricultura familiar moçambicana ainda não possui tanto apoio técnico quanto a brasileira. Já que, no Brasil existem órgãos governamentais especializados neste suporte, como a Empresa de Assistência Técnica e Extensão Rural - EMATER, e linhas de crédito a baixo custo subsidiadas pelo governo, como o Programa Nacional de Fortalecimento da Agricultura Familiar (PRONAF), que financiam a implantação, ampliação ou modernização da produção da agricultura familiar (BNDES, 2019).

Dentre as técnicas aprendidas, os professores interlocutores ficaram surpresos e demonstraram grande interesse pelo projeto de pesquisa e extensão desenvolvido pelo Time Enactus do IFCE - campus Iguatu3. Trata-se do Projeto Mudas, criado por estudantes de Iguatu, que utiliza um sistema de irrigação feito com palito de pirulito, prego e arame, contribuindo para atenuar impactos da seca de forma simples e barata (DIÁRIO DO NORDESTE, 2016). Este projeto tem como objetivo a produção segura de alimentos a baixo custo, mediante o sistema de reuso de água junto às tecnologias alternativas.

As comunidades beneficiadas com esse projeto de extensão estão no centro-sul do Ceará, local severamente afetado pela seca, que desde 2012 atinge os estados do nordeste brasileiro. Os professores entrevistados disseram que vão tentar implantar um sistema semelhante ao desenvolvido pelo Projeto

\footnotetext{
3 A Enactus é uma organização internacional sem fins lucrativos. Atualmente está presente em 36 países e conta com a participação de mais de 65 mil membros. Segundo dados da Enactus Brasil, há no país mais de 2500 estudantes engajados em 100 times, que tocam 135 projetos de empreendedorismo social em mais de 40 instituições de ensino superior participantes, dentre elas o IFCE-campus Iguatu (ENACTUS, 2019).
} 
Mudas em suas comunidades, visto que chega a ser 95\% mais barato que outros sistemas de irrigação de baixo custo disponíveis no mercado.

Ao comparar as condições da educação de ambos os países, os interlocutores colocam em melhor posição o Brasil. Afirmam que, ao contrário de Moçambique, nos Institutos Federais e Universidades do Brasil existe um tripé de ensino, pesquisa e extensão. A esse respeito um dos entrevistados explicou que, "aqui tem ensino, pesquisa e extensão dentro dos institutos e universidades, mas no nosso caso é apenas ensino, não existe nem a pesquisa, nem a extensão". Cabe destacar que esse tripé percebido pelos moçambicanos é uma garantia legal existente no Brasil, instituída pela Constituição Federal, em seu artigo 207: "As universidades gozam de autonomia didático-científica, administrativa e de gestão financeira e patrimonial, e obedecerão ao princípio de indissociabilidade entre ensino, pesquisa e extensão”.

Os professores moçambicanos valorizam também em seus discursos o fato de esses Institutos Federais atuarem em rede, "aqui é uma rede, que é uma rede chamada de Institutos Federais e neles há uma similaridade naquilo que é a programação do ensino”. Na opinião de um dos entrevistados, o método brasileiro é mais vantajoso por permitir maior proximidade da instituição de ensino com as comunidades, transmitindo o conhecimento e as pesquisas implantadas. Nesse discurso perpassa mais uma vez a preocupação dos moçambicanos com a coletividade. Postulam que como em Moçambique a pesquisa é gestada por outro órgão do governo, não pelas instituições de ensino onde os resultados das pesquisas poderiam ser disseminados por estudantes, impede uma ampla divulgação dos conhecimentos ao público alvo que é a comunidade. Como afirmam dos entrevistados, “essas informações acabam ficando restritas e concentradas. Fica reduzido, não alcança a todos os interessados" (ENTREVISTADO 2)

Outra desvantagem de Moçambique em relação ao Brasil, colocada na entrevista, é o fato de que em Moçambique, a partir do "Ensino Secundário" (Ensino Médio no Brasil) não existe ensino público gratuito, embora os valores não sejam elevados e existam algumas bolsas concedidas pelo governo ou outras organizações. Além disso, o número de vagas em universidades públicas é reduzido, restando as onerosas universidades privadas. Segundo um dos 
entrevistados, por tal motivo, muitos pais preferem enviar seus filhos para estudar em outros países, de preferência no Brasil. Parafraseando o argumento de Subuhana (2007, p. 325), entre os motivos que impulsionam a atual mobilidade dos moçambicanos para o Brasil, é o menor preço nas matrículas nas Universidades, o baixo custo de vida e os convênios.

\begin{abstract}
Vale notar que, em termos de custos, sai mais barato mandar um filho prosseguir seus estudos em uma universidade brasileira do que matriculá-lo numa universidade particular moçambicana ou mesmo mandá-lo para uma instituição de ensino europeia, australiana ou dos EUA, por exemplo. O custo de vida do Brasil seria mais baixo que os países citados. A oportunidade também é apontada como um dos fatores que traz esses estudantes ao Brasil. E os convênios educacionais existentes entre Brasil e Moçambique facilitam este acesso. (SUBUHANA, 2007, p. 325)
\end{abstract}

Quanto ao legado do intercâmbio entre Brasil e Moçambique no âmbito cultural, os moçambicanos afirmaram nas conversas que a relevância da viagem para o Brasil é ter possibilitado não apenas um intercâmbio acadêmico, mas também cultural. Como disse um dos interlocutores, "foi uma verdadeira troca de experiências e conhecimentos culturais. Uma diversidade de situações presenciadas e vividas. Mas não deixo de focalizar como mais importante o que está ligado com a experiência técnica”.

Em seus discursos, os entrevistados consideram que a globalização contribui para que os estilos de vida entre os países sejam semelhantes. Fato que se expressa em práticas recreativas. A esse respeito, um dos interlocutores disse que no que ele viu durante o tempo que passou no Brasil "o divertimento que existe cá é similar, nos finais de semana as pessoas saem para se divertir”. Outro fato que segundo os entrevistados aproxima culturalmente os países é a origem histórica comum, pois moçambicanos e brasileiros foram colonizados por Portugal. Essa consideração vai ao encontro das ideias do ator e pesquisador moçambicano, Ivan Laranjeira, em entrevista ao site Africultures. Para ele, de modo geral, Moçambique considera o Brasil um país irmão. Não só pela língua comum, mas pelo passado comum (LARANJEIRA, 2019).

O posicionamento do Brasil no âmbito internacional, contribui para que em Moçambique, ao igual que em muitos países, exista um amplo consumo de produtos culturais brasileiros, como novelas, programas de televisão, a paixão 
pelo futebol e a música. Sobre a música um dos entrevistados disse que "a música brasileira é muito consumida em Moçambique, por exemplo o Zezé di Camargo, Roberto Carlos, Paula Fernandes e por aí” (ENTREVISTADO 3).

Um dos assuntos colocados nas conversas como demarcador de fronteiras culturais é a diferente concepção brasileira e postura governamental em relação a homossexualidade. Apenas em julho de 2015, o Código Penal de Moçambique deixou de considerar crime a homossexualidade (DEUTSCHE WELLE, 2018). No antigo código, escrito em 1886, a homossexualidade seria uma prática antinatural e, como tal, deveria ser desencorajada e reprimida com sanções criminais. Contudo, os entrevistados não demonstraram em suas falas uma censura a este tipo de identidade sexual. Uns comentaram que embora os homossexuais não sejam perseguidos em Moçambique, como ocorre em alguns países africanos, é concebida pela população como uma prática que vai contra a sua cultura local. Um dos entrevistados chegou a comentar que é difícil encontrar com homossexuais em seu país, ao contrário do que acontece no Brasil.

Bem, aqui temos a questão da legalização da homossexualidade, que lá ainda não existe. Então é uma diferença. Que dizer não existe uma punição, mas é difícil se verificar isto lá. Se existe algumas pessoas do tipo, dificilmente se abrem. A gente só vê isso nas mídias. Aqui quando chegamos: nossa, tem bastante! (ENTREVISTADO 2)

Nas falas fizeram alusão às diferenças de gênero. Um dos entrevistados comentou, demonstrando contentamento, que achou as mulheres daqui mais emancipadas e considerou que elas agem com mais liberdade do que em Moçambique. Esta apreciação tem a ver com o argumento de Santana (2016). Esse autor destaca que elementos culturais (poligamia, ritos de iniciação, casamentos forçados, lobolo, organização social etc), alguns ainda presentes em Moçambique, potencializam a dominação secular à qual a mulher foi submetida. Tanto em relação a homossexualidade quanto ao comportamento feminino com maior autonomia, os entrevistados destacaram que na sociedade moçambicana estas situações continuam sendo de difícil aceitação devido à forte influência tradicional e cultural.

Contudo, um dos entrevistados fez a ressalva de que, apesar da liberdade feminina no Brasil, as mulheres brasileiras não se aproximaram deles. Ele 
interpreta essa atitude das mulheres em relação aos professores moçambicanos como uma possível manifestação de discriminação, mas ficou em dúvida se fundamentada na diferença racial ou de nacionalidade.

Ao serem indagados se vivenciaram práticas de exclusão no Brasil, todos os entrevistados falaram que presenciaram alguma situação de segregação racial. E um dos entrevistados foi vítima de racismo ao ser atendido por um servidor de uma agência bancária, na primeira semana no país. Também houve relatos de exclusão por parte dos estudantes dos institutos. Um dos interlocutores disse que se negaram a participar da troca de conhecimentos. Não havia, como em Moçambique, um responsável pelo coletivo estudantil que lhes apresente a instituição e seus ambientes. "Não encontramos com grupos de alunos do Brasil. A tendência é eles se afastarem. Se é por algum preconceito ou porque é uma forma cultural deles, não sei. O fato é que não demonstravam vontade de se comunicar conosco" (ENTREVISTADO 2)

A análise dos discursos referentes à experiência dos moçambicanos nas relações com brasileiros, apoiada nas teorias de Elias e Scotson (2000), permite pensar na diferenciação existente entre preconceito individual e a estigmatização grupal praticada pela sociedade. A primeira resulta de uma personalidade individualizada, enquanto a segunda, corresponde ao fato de um grupo rotular negativamente ao outro, causando fragilidades e atritos no relacionamento entre os agrupamentos sociais distintos.

No caso em análise, perpassa a estigmatização dos moçambicanos fundamentada em diferenças étnicas e raciais. De acordo com Silva (2017), um problema enfrentado pelo imigrante africano no Brasil é a discriminação étnica e racial. Langa (2014) também ressalta “a existência de múltiplas representações acerca da presença africana, destacando-se visões estigmatizantes perpassadas de preconceito racial pela condição de negro". Confirmando estas informações, Subuhana (2007, p. 331) destaca o "preconceito racial como a principal causa do mal-estar de um número considerável de nossos interlocutores em terras brasileiras”. O autor também informa que a imagem construída pelo brasileiro sobre os negros africanos costuma ser bastante negativa, pois associam a África apenas a guerras, selva, 
pobreza e miséria. Desta forma, o negro africano fica exposto a palavras e atos preconceituosos e estigmatizantes (SUBUHUNA, 2007).

À luz das teorias de Schiller e Salazar (2013), a atual crise econômica é acompanhada do crescimento de um nacionalismo metodológico, que reforça as fronteiras nacionais e étnicas. Nesse contexto, sob o argumento da proteção da soberania nacional, olha-se com desconfiança ao sujeito migrante, percebe-se nele uma ameaça para a estabilidade econômica, vagas de emprego, a cultura e a identidade nacional.

Apesar destas manifestações de discriminação racial e étnica enfrentadas na convivência com brasileiros, os moçambicanos entrevistados ressaltaram que a viagem ao Brasil, no geral, foi uma experiência cultural e acadêmica positiva. Foram unânimes em falar que voltariam ao país para um novo treinamento e até para turismo. Apesar dos pontos negativos, todos os entrevistados relatam que o "acolhimento" foi um dos pontos mais positivos encontrados na viagem, principalmente pelas "pessoas responsáveis pela coordenação dos treinamentos, professores envolvidos, que deram seu máximo" (ENTREVISTADO 4). Um dos entrevistados ressalta inclusive que a percepção que tinha e continuará tendo é que o Brasil é um país acolhedor e alegre.

Além da experiência acadêmica, os grupos viveram uma espécie de imersão no cotidiano local, ao participar das atividades diárias no espaço do ensino, convivendo com professores e técnicos administrativos de cada campus, dentro e fora dos muros institucionais (JORNAL A PRAÇA, 2018). Os entrevistados contam que foram em eventos acadêmicos e culturais, frequentaram restaurantes com servidores das instituições, fizeram compras em feiras dos mercados municipais, ou seja, vivenciaram uma parte do dia a dia local. Assim, "além do aprendizado de tudo que viram e viveram, levam também a saudade de um povo alegre, hospitaleiro e acolhedor" (JORNAL A PRAÇA, 2018). 
Figura 01: Grupo de Moçambicanos em Visita ao IFCE-campus Iguatu

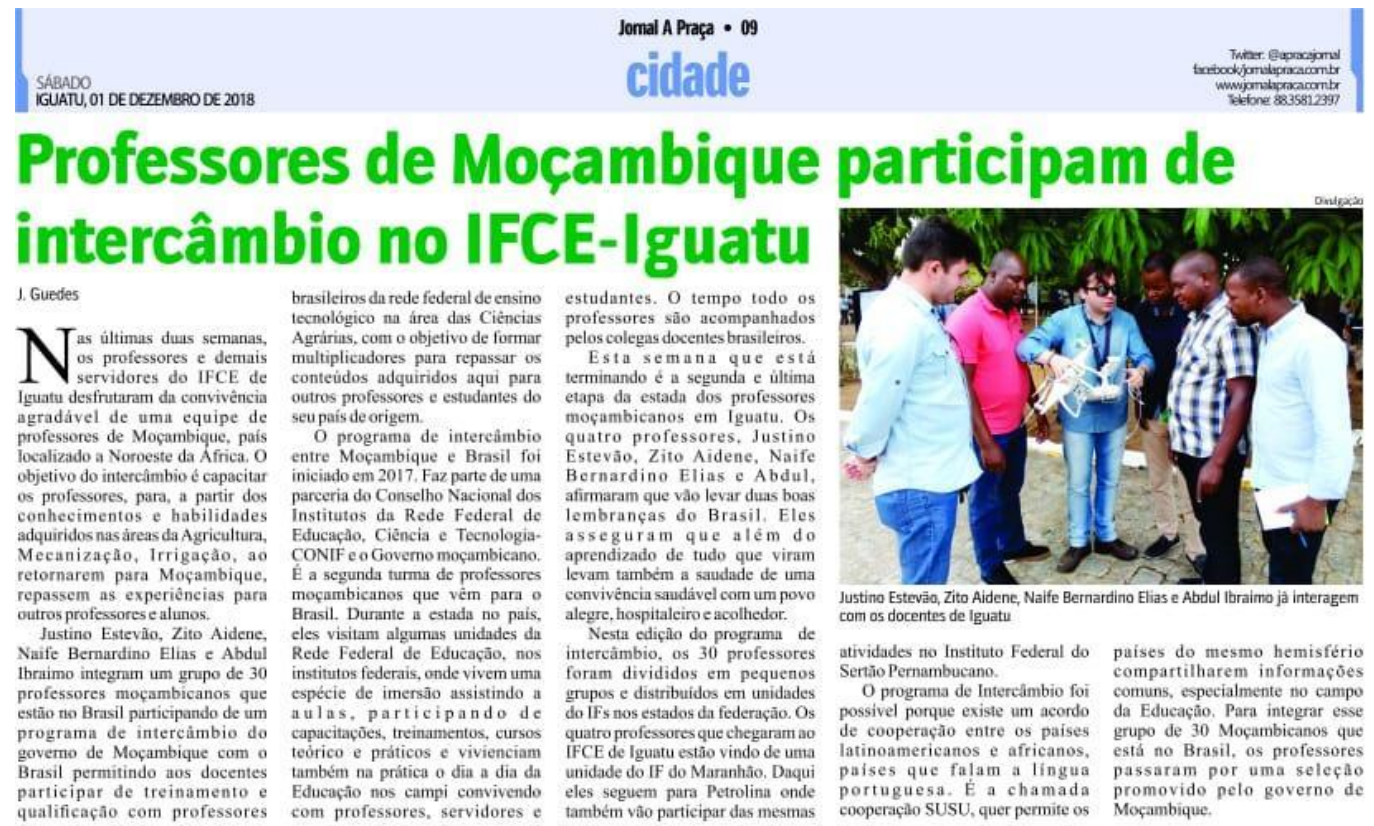

Fonte: Jornal A Praça, 2018.

\section{CONSIDERAÇÕES FINAIS}

Conforme pode-se observar nas entrevistas, mais do que uma experiência acadêmica, os moçambicanos tiveram um intercâmbio cultural valioso. Os moçambicanos vieram ao Brasil devido a projetos educacionais e profissionais e através destes objetivos surgem também os projetos transnacionais, devido a necessidade de levar conhecimento técnico para implantar na extensão rural de suas comunidades, famílias e trabalhos. Mais do que um projeto acadêmico individual, as experiências proporcionadas por essa mobilidade são um projeto institucional, ou seja, os entrevistados priorizam a questão coletiva de proporcionar desenvolvimento às instituições que estão ligados e consequentemente as suas regiões e país de origem.

Apesar da experiência positiva e a visão geral de um Brasil alegre e acolhedor, alguns elementos culturais interferiram na realização destes projetos, tais como: o preconceito étnico e racial dos brasileiros em face dos moçambicanos e a percepção moçambicana estigmatizada sobre a homossexualidade. Cabe destacar que os preconceitos são destacados por Silva (2017), Langa (2014) e Subuhana (2007) como grandes dificuldades enfrentadas 
pelo imigrante africano no Brasil. Estes elementos, representaram uma barreira cultural entre os dois países, a qual não foi o suficientemente forte para impedir uma troca de experiências técnicas e conhecimentos culturais, na diversidade de situações presenciadas e vividas no Brasil.

\section{REFERÊNCIAS}

Agência Brasileira de Comunicações. Cooperação Sul-Sul: Moçambique, 2012. Disponível em <http://www.abc.gov.br/Projetos/CooperacaoSulSul/Mocambiq ue>. Acesso em fevereiro de 2019.

. Histórico da Cooperação Técnica Brasileira, 2019, a. Disponível em <http://www.abc.gov.br/cooperacaotecnica/historico >. Acesso em janeiro de 2019

Cooperação Sul-Sul. 2019, b. Disponível em

<http://www.abc.gov.br/projetos/cooperacaosulsul>. Acesso em janeiro de 2019.

BALLERINI, D. SILVA, M. A. Por uma pedagogia da mobilidade: notas sobre migrações estudantis. Textura - Revista de Educação e Letras, v.17 n. 34, mai./ago.2015

BNDES. Pronaf - Programa Nacional de Fortalecimento da Agricultura Familiar. Disponível em <https://www.bndes.gov.br/wps/portal/site/home/financiamento/produto/pr onaf $>$. Acesso em março de 2019.

BRASIL, Constituição da República Federativa do Brasil de 1988. Disponível em<http://www.planalto.gov.br/ccivil_03/Constituicao/Constituicao.htm> Acesso em janeiro de 2019.

Disponível em

Resolução Normativa no 124/2016. Conselho Nacional de Migração.

<http://pesquisa.in.gov.br/imprensa/jsp/visualiza/index.jsp?jornal=1\&pagina $=179 \&$ data $=22 / 12 / 2016>$. Acesso em janeiro de 2019 .

CASTRO, A. A; NETO, A. C. O ensino superior: a mobilidade estudantil como estratégia de internacionalização na América Latina. Revista Lusófona de Educação, 21, 69-96, 2012.

CHEMIN, B. F. Manual da Univates para trabalhos acadêmicos:

planejamento, elaboração e apresentação. 3 ed. Lajeado: Ed. da Univates, 2015.

CONIF. Plano de Formação de Formadores de Moçambique no Brasil - Ciências Agrárias. Brasília, 2017. 
Deutsche Welle. Comunidade LGBT em Moçambique é discriminada? https://www.dw.com/pt-002/comunidade-lgbt-em-mo\%C3\%A7ambique\%C3\%A9-discriminada/a-46703995

DIÁRIO DO NORDESTE. 2015, a. Educação que Liberta. Disponível em: <http://diariodonordeste.verdesmares.com.br/cadernos/cidade/educacao-queliberta-1.1006990 >. Acesso em abril de 2018

Projeto de irrigação criado por jovens do CE ajuda luta contra a seca no Interior. Disponível em <http://diariodonordeste.verdesmares.com.br/edito rias/regiao/online/projeto-de-irrigacao-criado-por-jovens-do-ce-ajuda-lutacontra-a-seca-no-interior-1.1676538> Acesso em janeiro de 2019.

ELIAS, N.; SCOTSON, J. L. Os estabelecidos e os outsiders: sociologia das relações de poder a partir de uma pequena comunidade. Rio de Janeiro: Jorge Zahar Ed, 2000.

ENACTUS. Quem Somos. Disponível em <http://www.enactus.org.br/aboutus/> Acesso em janeiro de 2019.

FONSECA, D. J. De Migração em Migração se constroem Impérios, Reinos e Cidades: o africano no contexto da Globalização. In: MALOMALO, B., FONSECA, D. J, BADI, M. K. (Org). Diáspora Africana e Migração na era da Globalização: experiências de refúgio, estudo e trabalho. - 1 ed - Curitiba, PR: Editora CRV, 2015.

IFCE. Iguatu recebe professores moçambicanos para capacitação, 2018. Disponível em https://ifce.edu.br/iguatu/noticias/ifce-campus-iguatu-recebeprofessores-mocambicanos-para-capacitacao-em-irrigacao.

Jornal Notícias. REFORMA DA EDUCAÇÃO PROFISSIONAL: Governo moderniza ensino-técnico. Disponível em <http://www.jornalnoticias.co.mz/index.php/sociedade/77077-reforma-daeducacao-profissional-governo-moderniza-ensino-tecnico. Acesso em dezembro de 2018.

Jornal A Praça, 2018. Professores de Moçambique participam de intercâmbio no IFCE-Iguatu.

LANGA, E. N. B. Diáspora africana no Ceará: Representações sobre as festas e as interações afetivosexuais de estudantes africano(a)s em Fortaleza. Revista Lusófona de Estudos Culturais. Vol 2, 2014.

Diáspora Africana no Ceará no Século XXI: Ressignificações identitárias e as interseccionalidades de raça, gênero, sexualidade e classe no contexto da migração estudantil internacional. In: MALOMALO, B., FONSECA, D. J, BADI, M. K. (Org). Diáspora Africana e Migração na era da Globalização: experiências de refúgio, estudo e trabalho. - 1 ed - Curitiba, PR: Editora CRV, 2015. 
. Diáspora africana no Ceará no Século XXI: Ressignificações Identitárias de Estudantes Imigrantes. Tese (doutorado) - Universidade Federal do Ceará, Programa de Pós-graduação em Sociologia. Fortaleza, 2016.

LARANJEIRA, I. Le Mozambique considère le Brésil comme un pays frère. Disponível em <

http://africultures.com/6-le-mozambique-considere-le-bresil-comme-un-paysfrere13041/?utm_source=newsletter\&utm_medium =email\&utm_campaign=434> Acesso em janeiro de 2019.

MOÇAMBIQUE. Plano Estratégico de Educação e Cultura: Fazer da escola um pólo de desenvolvimento consolidando a Moçambicanidade, 2006. Disponível em

http://planipolis.iiep.unesco.org/sites/planipolis/files/ressources/mozambique _peec_por.pdf. Acesso em janeiro de 2018

. Programa de Apoio ao Sistema de Educação Técnico Profissional e Vocacional em Moçambique: Plano Operacional Geral, 2008.

. Protocolo de Intenções entre o Ministério da Ciência e Tecnologia, Ensino Superior e Técnico Profissional da República de Moçambique e o Conselho Nacional das Instituições da Rede Federal de Educação Profissional, Científica e Tecnológica da República Federativa do Brasil. Maputo Moçambique, 2017.

MORALES, L. I. M. Migração no México: tendências e consequências. In: Migração e políticas sociais. Cadernos Adenauer X (2009), $\mathrm{n}^{0}$ 1. Rio de Janeiro: Fundação Konrad Adenauer, agosto 2009.

MUANAMOHA, R. C.; RAIMUNDO, I.M. Cartografia da migração interna em Moçambique entre 1997 e 2007. REMHU, Revista Interdisciplinar Mobilidade Humanidade, Brasília, v. 26, n. 54, dez. 2018, p. 31-59 3

PATRÍCIO, G; PEIXOTO, J. Migração Forçada na África Subsaariana: Alguns Subsídios sobre os Refugiados em Moçambique. Dossiê: "Migrações na África: sujeitos, impactos e desafios". REMHU, Revista Interdisciplinar de Mobilidade Humana, Brasília, v. 26, n. 54, dez. 2018, p. 11-30

PINTO, A. P. dos S. Evolução e Caracterização do Ensino Técnico e Profissional em Moçambique: Expectativas e Percepções. Tese (doutorado) Instituto Universitário de Lisboa, Departamento de Ciência Política, Doutorado em Estudos Africanos. Lisboa, 2015.

RIBEIRO. F. A. Estratégia Geoeducacional na Cooperação Sul-Sul: uma análise dos projetos das Universidades de Integração Internacional - UNILA e UNILAB. Tese (doutorado) - Universidade Federal do Ceará, Programa de PósGraduação em Geografia. Fortaleza, 2016. 
RIZZI, K. R. Relações Brasil-Palop: 40 Anos de Cooperação para o Desenvolvimento no Atlântico Sul (1974/75-2015). Revista Brasileira de Estudos Africanos. v.1, n.1, Jan./Jun. 2016 | p.143-167.

SANTANA, C. S. O olhar da Frelimo sobre a emancipação feminina. Revista África(s), v. 03, n. 05, p. 157-168, jan./jun. 2016

SERVIÇO PASTORAL DOS IMIGRANTES. Disponível em <https://spmigrantes.wordpress.com/2012/04/05/brasil-na-rota-dosimigrantes-africanos/amp/> Acesso em março de 2019.

SCHILLER, N.G. SALAZAR, N.B. Regimes of Mobility Across the Globe. Journal of Ethnic and Migration Studies. February, 2013

SEYFERTH. Apresentação. In NETO, H.P.; SANTOS, M.; PETRUS, R.; GOMES, $\mathrm{C}(\mathrm{Org})$. Caminhos da migração: memória, integração e conflitos. $2^{\mathrm{a}} \mathrm{ed}$. $-\mathrm{E}-$ book - São Leopoldo: Oikos, 2015.

SILVA, A.S. Bolivianos em São Paulo: entre o sonho e a realidade. Estudos Avançados 20 (57), 2006.

SILVA, A. G. D da. Diáspora africana no Ceará: um estudo sobre a trajetória de estudantes africanos nas Universidades do Ceará. Revista UNIFEV:

Ciência \& Tecnologia, v. 3, 2017.

SOUSA, A. D. de. O programa de estudantes-convênio de graduação na Universidade Federal da Bahia: percepção dos estudantes PEC-G oriundos dos Países Africanos de Língua Oficial Portuguesa - anos 2009 - 2013. Dissertação (mestrado) - Universidade Federal da Bahia. Programa de Pós Graduação Estudos Interdisciplinares sobre a Universidade, Salvador, 2015.

SUBUHANA, C. Estudantes moçambicanos no Rio de Janeiro, Brasil: sociabilidade e redes sociais. Imaginario, São Paulo, v. 13, n. 14, p. 321355, jun. 2007 .

. O estudante convênio: a experiência sócio-cultural de universitários da África lusófona em São Paulo, Brasil. Anais da $26^{a}$ reunião brasileira de antropologia, 2008.

. A experiência sociocultural de universitários da África Lusófona no Brasil: entremeando histórias. Pro-Posições [online]. 2009, vol.20, n.1 [cited 2019-01-24], pp.103-126.

TCHAM, I. Estar, ficar e retornar: Estudantes africanos no Brasil e os dilemas da migração. Tese (doutorado) - Universidade Federal de Pernambuco, CFCH. Programa de Pós-Graduação em Antropologia, Recife, 2016.

TERRA. Imigração africana no Brasil aumenta 30 vezes entre 2000 e 2012. Disponível em<https://www.terra.com.br/noticias/brasil/imigracao-africanano-brasil-aumenta-30-vezes-entre-2000-e- 
2012,bcdedc77d62e5410VgnCLD200000odc6eboaRCRD.html> Acesso em janeiro de 2019.

ZAMBERLAM, J. et al. Estudantes internacionais no processo globalizador e a internacionalização do ensino superior. Porto Alegre: Solidus, 2009.

Recebido em 25 de novembro de 2019 Aprovado em 17 de julho 2020 